\title{
On Selecting Strategies of FTA Partners
}

\author{
Chu-Chuan Hsu \\ Department of Marketing and Logistics Management, Yu Da University of Science and Technology, Taiwan \\ Email: edison9@ydu.edu.tw
}

Received 3 March 2016; accepted 28 May 2016; published 31 May 2016

Copyright (C) 2016 by author and Scientific Research Publishing Inc. This work is licensed under the Creative Commons Attribution International License (CC BY). http://creativecommons.org/licenses/by/4.0/

c) (i) Open Access

\begin{abstract}
Via the intra-industry trade Cournot model in heterogeneous goods, the study deals with the strategies of how to select partner countries of free trade agreement on basis of social welfare criteria of a country. Thus, it gets the following results: Firstly, in a two-side FTA lowers tariffs on imports from any-member states. The FTA established on the similar market size of states. To establish a one-step global FTA is easier than other ways. Finally, as for allied strategies of the FTA, the first priority big country wants to ally itself with is a medium-sized country, the second one of which is a small country. Nevertheless, it is likely that big country will never have allies; the top priority a medium-sized country wants to ally itself with is a big country; a small country is willing to ally itself to any country.
\end{abstract}

\section{Keywords}

Economic Integration, Intra-Industry Trade, Bilateralism, Multilateralism

\section{Introduction}

Recently, the global community has started a fever of economic integration. For example, be expected to set up the Asia-Pacific free trade area (FTAAP) in the 2009 APEC meeting, EC eastern expansion in 2004, NAFTA, CACM and MERCOSUR are scheduled to create America Free Trade Area. In 2003 year end, China separately enter CEPA contracts with Hong Kong and Macau and also promoted the plans for ASEAN plus one (China) and ASEAN plus three (China, Japan and Korea). All the said development revealed the international tide is rampantly proceeding.

The Free Trade Area (FTA) is a type of economic integration. The meaning of economic integration is aimed to remove the confinement on trading obstructions and the movement of production factors between two nations. As such, it triggers the process with the market integrated with commodities, service and production factors and 
FTA is only the first step for economic integration ${ }^{1}$.

About the member selection of economic integration, taking EU for example, all nations desiring to join EU, must be featured with economic conditions meeting the requirement of Maastricht Treaty signed by EU Common Market members in 1992. Namely, all EU member nations are required to adjust their own economic conditions to meet the requirement of Maastricht Treaty and thereafter they are just allowed to join EU. The member qualification for EU is a type of inward convergent economic integration. The North America Free Trade Area is different. The emphasis of economic integration members is focused on the considerations of geography proximity, industry division and transportation cost and it is typically a structure-loose economic integration. Why do the conditions of economic integration show such variance? This article is aimed to discuss the issue of member nation selecting for free trade areas and it is aimed to propose relevant explanation and solutions.

Regarding the researched relevant to the welfare effect of economic integration exerted onto members and non-members, Viner [1] firstly proposed the notion of trade creation effect and trade diversion effect. Trade creation effect means goods are newly imported from the members with lower costs but the original import from other higher-cost nations outside the free trade areas are stopped. Creation effect means the import of goods are newly imported from lower-cost members but goods originally imported from higher-cost nations outside the free trade areas are stopped. The torsion caused by tariff can be well calibrated but trade diversion effect shows the opposite effect with its aim for protecting members but with the distorted markets left. The situation makes the nation-wide welfare damaged after economic integration. In addition, in view the whole global welfare, bilateral or regional economic integration cannot absolutely assure of promoted global trade freedom and welfare. Such a situation causes some conflicts happening to economic integration (called bilateralism) and the multilateralism in GATT/WTO.

Taking the measurement based on social welfare for example, under the condition that Kemp and Wan [2] proposed the beneficial arrangement of no damage to custom unions, every nation member under the custom unions can reach the conditions with pareto improvement through transferring payment systems among persons and nations. These conditions comply with relevant requirements listed in Term 5 Article 25, GATT ${ }^{2}$. Krishna and Panagariya [3] further proposed the criteria similar to Kemp and Wan [2]. However under the conditions suitable for FTA, the proposed two norms were aimed to eliminate the conflict happening to two disputes of both multilateralism and bilateralism. Even so, some factors originated from various national industry structures, markets and culture variance still drives economists toward forward various theories to delineate the conflict relation between both proposals.

Firstly, Kennan and Riezman [4], Richardson [5], Bagwell and Staiger [6] and Ornelas [7] supposed under the premise with the occurrence of trade creation, FTA came with incentibes to reduce their external tariff with the discrimination to outsiders alleviated. This situation brought without conflict to the said both proposals. Namely, economic integration cab trigger the global trade liberalization.

On the other hand, through the design of transportation cost and culture variance, Krugman [8] put forward the natural trade block theory and he supposed the world could be divided into 3 major blocks, North America, Europe and East Asia due to some factors like geography and culture. This situation would impede the permeation of multilateralism. Grossman and Helpman [9], in view of economic politics, testified trade diversion was exactly the driving force to reach trade protocols to result in the conflict happening to both proposals. Panagariya and Findlay [10] indicated when preferential trade agreements were reached with lees customs protection among members. Because the wage levels within the trade areas were reduced, labor teams would host more lobbying activities to rise the tariff of nations outside the trade areas with protection formed. Levy [11] and Krishna [12] used various modal designs and also reach similar results. Because multilateral trade liberalization reduced the profit of nations (suppliers) originally belonging to bilateral preferential agreements. Suppliers would host political lobbying activities to impede the proceeding of multilateral free trade. Bond, Riezman and Syropoulos [13] use the 3-nation model to explore effect of strategically trade policies exerted on FTA. In the article, they found when FTA was scaled up, the relative market status and welfare would exceed the global av-

\footnotetext{
${ }^{1}$ According to the degree of economic integrating, in man increasing order, they are separately: preferential trading arrangement, free trade areas, customs unions, common markets and economic unions.

${ }^{2}$ In view of the forerunner of WTO, GATT is regulated at Article 24 Term 5 for CUs and FTA violating the rules of most-favored nations (MFN). The relevant regulations listed in GATT Article 24 Term 5, including some baselines. Among them, the most important baseline is aimed to promote trading activities no more trading barriers left in the said areas.
} 
erage. Thus, the free trade agreements (bilaterialism) with the ultimate goal for maximized welfare for member nations would impair the multilateralism claimed by WTO. Meanwhile, there were some scholars with the proposal that despite the conflict happening to proposals, they could be co-existent for the time being. Levy [11] also indicated reducing or increasing the tariff of nations outside the free trade areas depended on the economic features of FTA member nations. Ornelas [14] further found that when the establishment of FTA made trade creation happening but no trade diversion effect showing, trade creation effect would cause the results the same as those nations outside FTA without joining the free trade areas.

In addition, the trade creation and trade diversion concept of extension, Bhagwati and Panagariya [10] article pointed out that the difference in the importing country's optimal tariff and production costs of the exporting countries, importing countries will adopt low-cost (high-cost) exporting countries with high (low) tariffs, and therefore extends the establishment of a bilateral FTA with the low-cost countries, it will harm the importing country were criticized by the failure of social welfare results; Kiyono [15] to further the model of perfect competition from the $n$ homogeneous firms expanded to imperfect competition, get in there under the premise of the trade creation and economic integration (FTA) could become the second-best tariff policy choices.

As aforesaid, although whether FTA was established or not had been evaluated with relevant social welfare basis and trade effect, up to date, there was still no consistent conclusion and consensus reachable. This hardship clearly reflected the despiteful discussion happening to WTO every year. The issues discussed in this article included the selecting strategies for free trade partners in consideration of a nation's economic conditions (namely market scales as latter mentions said) with relevant determination basis and market structures included. It was also aimed to examine if the results indicated by Levy [11] and Krishna [12] was established under the structure mentioned herein. Also, under the condition with globally dramatic variance in economic development, the notion of tri-polarity trend happening but no unified free trade areas proposed by Krugman $\left(1991,1993^{3}\right)$ [8] [16] could be examined.

In this article, the linear demand functions were adopted to extend the 3-nation-3-finance design designed by Riezman [18] and Krishna [12]. The cross-nation oligopoly model proposed by Hsu et al. [19] was still used. Also, external effect of tariff adjustment policies was also taken into consideration ${ }^{4}$. Under the premise with maximized welfare, the selecting strategies for FTA partners were discussed and also, some issues relevant to a nation joining bilateral FTA and multilateralism were also considered. To sum up concretely, the research was aimed at below items:

1) Under the trading models in heterogeneous property industries, the way how to select a FTA partner?

2) Under the existing FTA, the conditions and conflicts for selecting secondary trading partners.

3) Under the research structure of this article, the probabilities to make global FTA happening?

4) In view of makers' profit, if it would be established under this research structure when the conflict between bilateralism and multilateralism was re-evaluated?

This article was divided into 5 sections. The 1st section was foreword. The 2nd section was the modal setting and analysis under the conditions of no FTA established. The 3rd section was the condition and welfare analysis to establish FTA. The 4th section was the strategy analysis for selecting FTA partners. The 5th section is conclusion and suggestion.

\section{The Basic Modal Setting and Analysis under the Condition of No FTA Established}

Firstly, it was assumed that there were three nations $i(i=\mathrm{A}, \mathrm{B}, \mathrm{C})$ and every nation owned its representative maker with products serving as heterogeneous substitute goods in markets of every nation. Also, the local and international transportation cost was leveled at zero ${ }^{5}$. Meanwhile, it was assumed that every national market could be isolated entirely; namely, it showed no phenomenon for import and export and no cross-nation moving on factors, either. Among them, let the nation A own a maker 1; let nation B own a maker 2 and nation C own a maker 3. Secondly, the representative maker of every nation was implementing their quantitative competition in

\footnotetext{
${ }^{3}$ Krugman [16] [17] simulated the correlation between FTA quantity and global welfare levels. It was found that when the product substitute flexibility was rated at 4 and tariff was leveled at $10 \%$, there would be the least welfare when only two FTAs existed in the world.

${ }^{4}$ Riezman [18] used a $3 \times 3$ model (3 nations and 3 independent goods) to explain the relevant analysis for the formation of tariff alliances. Krishna [12], under the hypothesis with the oligopoly competitive markets featured with multiple plants making homogenous goods, the formation and influence of FTA was analyzed. However, under the said analysis, it existed in no external natures of trading policies. Namely FTA establishment would not affect the external tariff for member nations.

${ }^{5}$ Following the design of Dixit [20].
} 
their own national market respectively ${ }^{6}$. The output supplying to nation $i$ was separately $q_{i}^{m}(m=1,2,3)$ and the total output was $Q^{m}=\sum_{i} q_{i}^{m}$. The average and marginal cost for production were $c$. Thirdly, let $t_{i}^{m}$ mean the quantity-based import tariff on maker m imposed the nation $i . P_{i}^{m}$ Meant the local price for $m$ types of goods in the nation $i$. Finally, the representative consumers in the nation $i$ was designated as the quadratic symmetric utility functions ${ }^{7}$ :

$$
U_{i}=q_{i}^{0}+a_{i}\left(\sum_{m} q_{i}^{m}\right)-\frac{b}{2}\left[\sum_{m} q_{i}^{m^{2}}+2 \theta\left(q_{i}^{1} q_{i}^{2}+q_{i}^{2} q_{i}^{3}+q_{i}^{1} q_{i}^{3}\right)\right]
$$

In above equation, $q_{i}^{0}$ meant the total consumption of other products in the nation $i$ to serve as the numeraie for trading balance. $a_{i}>c>0$ ( $c$ meant marginal cost, detailed as below.) $b>0$ and $\theta$ meant the parameters after heterogeneous processing. Also, $0<\theta<1$ meant the mutual substitutes. Also, in the said three nations, they all came with the substitute relation with consistency and symmetry. Meanwhile, in below description, the size of $a_{i}$ was used to express the market scale in the nation $i$. According to $P_{i}^{m}=\partial U_{i} / \partial q_{i}^{m}$, it could be found the reverse demand market of differential products in the nation $i$ were separately:

$$
\begin{array}{ll}
P_{i}^{1}=a_{i}-b\left(q_{i}^{1}+\theta q_{i}^{2}+\theta q_{i}^{3}\right), & \forall i=A, B, C \\
P_{i}^{2}=a_{i}-b\left(q_{i}^{2}+\theta q_{i}^{1}+\theta q_{i}^{3}\right), & \forall i=A, B, C \\
P_{i}^{3}=a_{i}-b\left(q_{i}^{3}+\theta q_{i}^{1}+\theta q_{i}^{2}\right), & \forall i=A, B, C
\end{array}
$$

It was known from above three equations, under the fixed values of $b$ and $\theta, a_{i}$ meant the market demand and scale of three types of goods in the nation $i$ were consistent. Additionally, availably let $Q_{i}^{1} \equiv q_{i}^{1}+\theta q_{i}^{2}+\theta q_{i}^{3}$ and it was named as the total purchase amount of the 1 st goods in the nation $i$. As might be deduced by analogy, $Q_{i}^{2}$ and $Q_{i}^{3}$ could be reached.

The social welfare function for every nation could be expressed by the equation as below:

$$
S W_{i}=U_{i}-c q_{i}^{m}+\pi_{-i}^{m}-\sum_{-m} P_{i}^{-m} q_{i}^{-m}+T R_{i}=C S_{i}+\pi_{i}^{m}+\pi_{-i}^{m}+T R_{i}
$$

In above equation, it indicated the social welfare in the nation (social welfare: $S W_{i}$ ) meant representative personal utility $\left(U_{i}\right)$ minus production cost of $m$ makers in the nation $\left(c q_{i}^{m}\right)$. The sum was further minus the total revenue ( $\sum_{-m} P_{i}^{-m} q_{i}^{-m}$ ) of foreign makers $(-m)$ the nation $i$ and plus the profit $\left(\pi_{-i}^{m}\right)$ of makers $(m)$ from the nation $i$ in the foreign markets $(-i)$, together with the addition of tariff revenue $\left(T R_{i}\right)$. In addition, $S W_{i}$ can also be designated as the addition of $C S_{i}, \pi_{i}^{m}, \pi_{-i}^{m}$ and $T R_{i}$. Among them, $C S_{i}$ meant the consumer surplus in the nation $i$, defined as $C S_{i}=U_{i}-P_{i}^{m} q_{i}^{m}-\sum_{-m} P_{i}^{-m} q_{i}^{-m}$. Also, to simplify the designation, let $\alpha_{i} \equiv a_{i}-c$. Taking the nation A for example, $t_{A}^{2}$ meant the quantity-based import tariff for the nation $\mathrm{A}$ to impose on makers from the nation B. $t_{A}^{3}$ meant the quantity-based import tariff for the nation A to impose three products from the maker C. The rest were deduced by similar analogy, also.

Through aforesaid hypothesis, it could be further deduced that under the originally existing tariff barriers, taking the nation A for example ${ }^{8}$, the balance exchange volume, import volume, balance prices, maker profit and social welfare for every nation were described as below:

$$
q_{A}^{1}=\frac{\alpha_{A}}{2 b(1+\theta)}+\frac{\theta\left(t_{A}^{2}+t_{A}^{3}\right)}{2 b(1+\theta)(2-\theta)}
$$

\footnotetext{
${ }^{6}$ As above, when every nation simultaneously and respectively determined the optimal import policies, the competition ways for three makers in three national markets were taken into consideration. It was known from the article proposed by Hsu et al. [18] (Also See the article proposed by Yang and Hwang [21]), under the hypothesis with substitute goods, makers in three nations would implement quantity-based competition.

${ }^{7}$ As for the deduction for setting and demand functions in forms of quadratic utility functions, please refer to Cable et al. [22].

${ }^{8}$ See the Appendix 1 for the balance exchange volume, import volume, balance prices, maker profit and social welfare with nation B and C.
} 


$$
\begin{aligned}
& q_{A}^{2}=\frac{\alpha_{A}}{2 b(1+\theta)}+\frac{\theta\left(t_{A}^{2}+t_{A}^{3}\right)-2(1+\theta) t_{A}^{2}}{2 b(1+\theta)(2-\theta)} \\
& q_{A}^{3}=\frac{\alpha_{A}}{2 b(1+\theta)}+\frac{\theta\left(t_{A}^{2}+t_{A}^{3}\right)-2(1+\theta) t_{A}^{3}}{2 b(1+\theta)(2-\theta)} \\
& Q_{A}^{1}=q_{A}^{1}+\theta q_{A}^{2}+\theta q_{A}^{3}=\frac{(1+2 \theta) \alpha_{A}}{2 b(1+\theta)}-\frac{\theta\left(t_{A}^{2}+t_{A}^{3}\right)}{2 b(1+\theta)(2-\theta)} \\
& P_{A}^{1}=\frac{\alpha_{A}}{2(1+\theta)}+c+\frac{\theta\left(t_{A}^{2}+t_{A}^{3}\right)}{2(1+\theta)(2-\theta)} \\
& P_{A}^{2}=\frac{\alpha_{A}}{2(1+\theta)}+c+\frac{\theta\left(t_{A}^{2}+t_{A}^{3}\right)+2\left(1-\theta^{2}\right) t_{A}^{2}}{2(1+\theta)(2-\theta)} \\
& P_{A}^{3}=\frac{\alpha_{A}}{2(1+\theta)}+c+\frac{\theta\left(t_{A}^{2}+t_{A}^{3}\right)+2\left(1-\theta^{2}\right) t_{A}^{3}}{2(1+\theta)(2-\theta)} \\
& \pi_{A}^{m}=b\left(q_{A}^{m}\right)^{2}, \quad m=1,2,3 \\
& S W_{A}=q_{A}^{0}+\frac{1}{8 b(2-\theta)^{2}(1+\theta)^{2}} \times\left\{4\left[5 \alpha_{A}^{2}+2\left(t_{A}^{2}+t_{A}^{3}\right) \alpha_{A}-3\left(t_{A}^{22}+t_{A}^{32}\right)+2\left(\alpha_{B}-t_{B}^{1}\right)^{2}+2\left(\alpha_{C}-t_{C}^{1}\right)^{2}\right]\right. \\
& +4 \theta\left[\alpha_{A}^{2}-3\left(t_{A}^{22}+t_{A}^{32}\right)+4 t_{A}^{2} t_{A}^{3}-2\left(\alpha_{B}-t_{B}^{1}\right)\left(\alpha_{B}+t_{B}^{1}-t_{B}^{3}\right)-2\left(\alpha_{C}-t_{C}^{1}\right)\left(\alpha_{C}+t_{C}^{1}-t_{C}^{2}\right)\right] \\
& +\theta^{2}\left[\left(t_{A}^{22}+t_{A}^{32}\right)+10 t_{A}^{2} t_{A}^{3}-2 \alpha_{A}\left(t_{A}^{2}+t_{A}^{3}\right)-19 \alpha_{A}^{2}+2\left(\alpha_{B}+t_{B}^{1}-t_{B}^{3}\right)^{2}+2\left(\alpha_{C}+t_{C}^{1}-t_{C}^{2}\right)^{2}\right] \\
& \left.+2 \theta^{3}\left[3 \alpha_{A}^{2}+\left(t_{A}^{2}-t_{A}^{3}\right)^{2}\right]\right\}
\end{aligned}
$$

In aforesaid equations, when both $t_{A}^{2}$ and $t_{A}^{3}$ were higher than $0, q_{A}^{1}>q_{A}^{2}, q_{A}^{1}>q_{A}^{3}, P_{A}^{2}>P_{A}^{1}$ and $P_{A}^{3}>P_{A}^{1}$ meant there was no tariff required. Local (taking the nation A for example, the same as below described) makers burdened lower competition cost in local markets. Thus, in view of local markets, the balance quantity and profit in markets for local makers were higher than those of foreign makers. Also, the balance price for local makers in markets was lower.

The most adequate import tariff determined by the maximization conditions for social welfare was ${ }^{9}$ :

$$
t_{i}^{m^{*}}=\frac{(2+\theta)(2-\theta)}{2\left(6+2 \theta-3 \theta^{2}\right)} \alpha_{i}, \quad i=\mathrm{A}, \mathrm{B}, \mathrm{C}
$$

Taking the nation A for examination, it was known from Equation (3) that $t_{A}^{2^{*}}=t_{A}^{3^{*}}$. It was because the production conditions in both nation $\mathrm{B}$ and $\mathrm{C}$ were consistent. Also, the products were the same as the differential parameters $\theta$ of products from the nation A. It meant local consumers viewed imported goods as the similar "foreign goods" and they were all homogenous substitute goods. Thus, they were also imposed with the same import tariff.

By using the Equation (3), the static analysis was implemented. Firstly, it was reachable that

$$
\partial t_{i}^{m^{*}} / \partial \alpha_{i}=\left(4-\theta^{2}\right) / 2\left(6+2 \theta-3 \theta^{2}\right)>0
$$

The Equation (4) meant the larger a national market scale it was, the higher the import tariff it would be naturally. It indicated that whenever the larger the local market it was, the higher willing the foreign makers showed

\footnotetext{
${ }^{9}$ See the Appendix 2.
} 
to share local markets with relatively more profit reachable. Thus, the local government showed higher intention to increase tariff aiming to transfer the said profit space. Secondly, it was reachable that

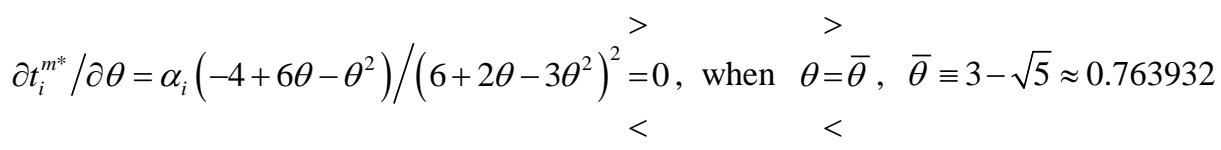

The Equation (5) meant whenever the differential parameters $\theta$ of products were raised, the influence on optimal import tariff $\theta$ depended on initial values. When $0<\theta<\bar{\theta}$, the increment of $\theta$ values would reduce the optimal tariff. It meant when trade goods showed lower initial substitute degrees, products naturally showed more difference. If product difference was reduced or substitute degrees were increased, governments would be forced to reduce the optimal tariff to make social welfare maximized. Taking $\theta$ initial values approximating to 0 for example, it meant when the difference of foreign products was maximized, it would be next to different goods. Under such a condition, it meant the import of foreign products was basically correlated to the profit of local makers, but it was highly correlated to local consumers. The said situation indicated that the tariff level determined by governments was mainly based on local consumption. Under this situation, when $\theta$ was increased, despite reduced tariff showing disadvantages to local makers, it was actually highly beneficial for local consumers. In other words, when $\theta<\bar{\theta}, t_{i}^{m^{*}}$ would decrease with $\theta$ increment. When $\bar{\theta}<\theta<1$, the increment of $\theta$ would make optimal tariff higher. It meant whenever the initial substitute degrees of trade goods were higher, it also meant the difference of products was lower. If the difference of products was further reduced or the substitute degrees were increased, governments were forced to increase optimal tariff for social welfare maximization. Identically, taking $\theta$ initial values approximating to 1 for example, it meant the difference of foreign goods was extremely small and they were almost the same goods. Under such a situation, it meant the import of foreign products basically posed higher influence on the profit of local makers but showed lower influence on local consumers. Under the said condition, governmental determination for tariff levels would be mainly based on local makers. Under such a situation, when $\theta$ was increased with higher tariff resulted, despite the disadvantages to local consumers, it was actually beneficial for local makers. Namely, when $\theta>\bar{\theta}, t_{i}^{m^{*}}$ would increase the increment of $\theta$.

\section{Proposition 1}

When the optimal import tariff locally (the nation A) was the same among various makers, it meant $t_{A}^{2}=t_{A}^{3}$ and showed positive correlation between the sizes and local market scales (the nation A). However, the correlation to $\theta$ was uncertain. When $\theta$ was comparatively higher, $t_{A}$ and $\theta$ were positively correlated. When $\theta$ was comparatively lower, $t_{A}$ and $\theta$ were negatively correlated.

From the results of Equation (3), it could be reachable that for every nation's basic social welfare levels of no FTA established, they were separately:

$$
S W_{i}^{*}=q_{i}^{0}+\frac{(17-9 \theta)\left(6+2 \theta-3 \theta^{2}\right) \alpha_{i}^{2}+(4-3 \theta)^{2} \sum \alpha_{-i}^{2}}{4 b\left(6+2 \theta-3 \theta^{2}\right)^{2}}, i=\mathrm{A}, \mathrm{B}, \mathrm{C}
$$

It was known from Equation (6). Under the fixed values of $q_{i}^{0}, \theta$ and $b$, the social welfare levels of various nations and the foreign market scales were positively correlated.

\section{The Analysis for Conditions and Welfare to Establish FTA}

In this section, based on the social welfare levels of no FTA established as the aforesaid section, the conditions to establish FTA were further described and FTA partner selection was also discussed. Firstly, the conditions for both nations (A and B) to establish FTA were analyzed with local makers in view of profit maximization for their attitude toward FTA. Thereafter, under existent FTA, the correlated influence on conditions and limitations with a given member nation (A) and a outsider nation (C) to bilaterally establish the FTA, together with another nation (B) and the alliance partners of a outsider nation (C). Finally, the conditions and relevant welfare analysis for a single global FTA were further discussed and analyzed.

1) The A-B FTA was established by both nation A and B.

After a new FTA was established by both nation A and B, then $t_{A}^{2}=t_{B}^{1}=0$. For any import tariff for the nation $\mathrm{C}$ imposed by both nation $\mathrm{A}$ and $\mathrm{B}$ became: 


$$
t_{i}^{3 A B}=\frac{2-\theta}{6+3 \theta-2 \theta^{2}} \alpha_{i}<t_{i}^{3^{*}}, \quad i=\mathrm{A}, \mathrm{B}
$$

It meant FTA establishment would simultaneously reduce the import tariff on products from regions outside FTA. The result was consistent to those proposed by Kennan and Riezman [4], Richardson [5], Bagwell and Staiger [6], and Ornelas [7]. Under the social welfare maximization made by governments, the tariff policies were featured with external natures (policy spillover). Taking the nation A for example, after the nation A established FTA with the nation B, makers in the nation B in the markets of the nation A would be more competitive than makers from the nation $\mathrm{C}$. Thus, to maximize the social welfare locally, the government from the nation $\mathrm{A}$ would synchronously reduce the import tariff imposed on the nation C outside FTA. It was aimed to enhance the competition of the makers from both nation $\mathrm{B}$ and $\mathrm{C}$ in local markets.

As such, the variance for balance exchange volume of makers from various nations in the markets of nation A was:

$$
\begin{aligned}
& \Delta q_{A}^{1}=-\frac{\theta(1+\theta)(3-\theta)}{b\left(6+2 \theta-3 \theta^{2}\right)\left(6+3 \theta-2 \theta^{2}\right)} \alpha_{A}<0 \\
& \Delta q_{A}^{2}=\frac{\left(12+6 \theta-5 \theta^{2}\right)}{2 b\left(6+2 \theta-3 \theta^{2}\right)\left(6+3 \theta-2 \theta^{2}\right)} \alpha_{A}>0 \\
& \Delta q_{A}^{3}=\frac{\theta(2+\theta)}{2 b\left(6+2 \theta-3 \theta^{2}\right)\left(6+3 \theta-2 \theta^{2}\right)} \alpha_{A}>0
\end{aligned}
$$

It was indicated from aforesaid equations. The establishment of A-B FTA, for local makers (nation A), the balance volume in local markets would be reduced due to the opening of local markets. However, the import volume from both nation B and C would be increased. Also, the increased volume in the nation B (a member nation) would be higher than that increased by the nation $C$ (nonmember nation) ${ }^{10}$. This situation indicated FTA establishment would bring about expanded effect no matter for the import from member nations or non-member nations.

\section{Preposition 2}

When the FTA was established by two nations, the import tariff imposed on non-member nations would be reduced simultaneously. As such, it would increase not only the import volume from member nations but also the import volume from non-member nations. Although the production output of makers from member nations was reduced, yet the export volume of member nations was increased. Thus, after FTA establishment, the total production output of local makers was reversely increased ${ }^{11}$.

Thereafter, for profit variance of maker 1 from the nation $\mathrm{A}$, it was designated with the equation as below:

$$
\Delta \pi^{1}=\frac{3\left(12+6 \theta-5 \theta^{2}\right)\left(20-2 \theta-13 \theta^{2}+4 \theta^{3}\right) \alpha_{B}^{2}-4 \theta(1+\theta)(3-\theta)^{2}\left(12+5 \theta-5 \theta^{2}\right) \alpha_{A}^{2}}{4 b\left(6+2 \theta-3 \theta^{2}\right)^{2}\left(6+3 \theta-2 \theta^{2}\right)^{2}}
$$

Firstly, became $\Delta Q_{A}^{1}>0$, it could be deduced that $\Delta P_{A}^{1}<0$. Also, $\Delta q_{A}^{1}<0$ was known, it could be found that the profit of maker 1 from local markets would be certainly reduced. However, the profit from the markets of member nations would be certainly increased. Secondly, the condition of $\Delta \pi^{1}>0$ deduced from equation (8) were:

$$
\alpha_{B} / \alpha_{A}>\delta_{1}, \quad \delta_{1} \equiv \sqrt{4 \theta(1+\theta)(3-\theta)^{2}\left(12+5 \theta-5 \theta^{2}\right) / 3\left(12+6 \theta-5 \theta^{2}\right)\left(20-2 \theta-13 \theta^{2}+4 \theta^{3}\right)}{ }^{12}
$$

As the above equation shown, only when market scale in the nation B was comparatively sufficient to market scale in the nation A, could the local makers from the nation A support to establish the A-B FTA.

\footnotetext{
${ }^{10}$ The increased import of the nation A from the nation C outside FTA was attributed to simultaneously import tariff imposed on the nation C reduced by the nation $\mathrm{A}$.

${ }^{11}$ If $\left(\alpha_{B} / \alpha_{A}\right)<\left[2 \theta(1+\theta)(3-\theta) /\left(12+6 \theta-5 \theta^{2}\right)\right]$, then $\Delta q_{A}^{1}+\Delta q_{B}^{1}<0$; otherwise $\Delta q_{A}^{1}+\Delta q_{B}^{1}>0$.

${ }^{12}$ Herein, $0<\delta_{1}<1.04595$.
} 
It was found from the positive correlation between $\delta_{1}$ and $\theta$, when the difference among products were more remarkable (lower $\theta$ ), due to less competition among makers, after A-B FTA establishment, the decrease amount of profit from local markets would be reduced. Thus, the relative market scale from the nation B was not large necessarily to compensate local market loss due to the cancellation of import tariff. When product difference among makers was not remarkable (higher $\theta$ ), due to violent competition among makers, after A-B FTA establishment, the decrease amount of profit from local markets would be higher. Thus, the relative market scale in the nation $\mathrm{B}$ had to be larger and then it was just available to compensate the loss of local markets due to the cancellation of import tariff.

Identically, it could be deduced that for makers in the nation B, the conditions of $\Delta \pi^{2}>0$ were $\alpha_{B} / \alpha_{A}<\delta_{1}^{-1}$ (or $\alpha_{A} / \alpha_{B}>\delta_{1}$ ).

The social welfare levels of FTA member nations were designated with the equation as below:

$$
S W_{i}^{A B}=q_{i}^{0}+\frac{(4-3 \theta)^{2} \alpha_{C}^{2}}{4 b\left(6+2 \theta-3 \theta^{2}\right)^{2}}+\frac{(8-3 \theta) \alpha_{i}^{2}}{2 b\left(6+3 \theta-2 \theta^{2}\right)}+\frac{(3-\theta)^{2} \alpha_{-i}^{2}}{b\left(6+3 \theta-2 \theta^{2}\right)^{2}}
$$

wherein, $i=\mathrm{A}, \mathrm{B},-i$ meant FTA partners. The social welfare for the non-member nation C was:

$$
S W_{C}^{A B}=q_{C}^{0}+\frac{(17-9 \theta) \alpha_{C}^{2}}{4 b\left(6+2 \theta-3 \theta^{2}\right)}+\frac{(2-\theta)^{2}\left(\alpha_{A}^{2}+\alpha_{B}^{2}\right)}{b\left(6+3 \theta-2 \theta^{2}\right)^{2}}
$$

Meanwhile, the optimal import target showed no slight difference between the nation C (non-member nation) and before the establishment of A-B FTA. However, due to the occurrence of trade expansion effect, the establishment of A-B FTA would improve the social welfare in the nation $\mathrm{C}^{13}$. The result was consistent to the proposals of Kemp and Wan, Krishna and Panagariya, together with GATT/WTO relevant baselines and norms.

In comparison of equation (10) and (6), it was known the increase and decrease of social welfare for member nations after FTA establishment were shown as below:

$$
S W_{i}^{A B}-S W_{i}^{*}=\frac{3\left(12+6 \theta-5 \theta^{2}\right)\left(20-2 \theta-13 \theta^{2}+4 \theta^{3}\right) \alpha_{-i}^{2}-(3-\theta)(2+\theta)\left(6+2 \theta-3 \theta^{2}\right)\left(6+3 \theta-2 \theta^{2}\right) \alpha_{i}^{2}}{4 b\left(6+2 \theta-3 \theta^{2}\right)^{2}\left(6+3 \theta-2 \theta^{2}\right)^{2}}
$$

Identically, the total variance of the social welfare between two member nations was:

$$
\sum_{i=A, B}\left(S W_{i}^{A B}-S W_{i}^{*}\right)=\frac{\left(504+72 \theta-654 \theta^{2}+72 \theta^{3}+220 \theta^{4}-79 \theta^{5}+6 \theta^{6}\right)\left(\alpha_{A}^{2}+\alpha_{B}^{2}\right)}{4 b\left(6+2 \theta-3 \theta^{2}\right)^{2}\left(6+3 \theta-2 \theta^{2}\right)^{2}}>0
$$

Knowing from aforesaid equation, both nations with FTA establishment would certainly improved the welfare sum. In other words, if there was a welfare transfer mechanism existent in member nations. It was well guaranteed FTA entry would assure of better welfare than before.

Through Equation (11), it could be deduced that the conditions to establish A-B FTA (Namely, both nation A and B satisfied Equation (11) with non-negative values shown) were:

$$
\delta_{A B} \leq \frac{\alpha_{B}}{\alpha_{A}} \leq \delta_{A B}^{-1}, \text { wherein } \delta_{A B} \equiv \sqrt{\frac{(3-\theta)(2+\theta)\left(6+2 \theta-3 \theta^{2}\right)\left(6+3 \theta-2 \theta^{2}\right)}{3\left(12+6 \theta-5 \theta^{2}\right)\left(20-2 \theta-13 \theta^{2}+4 \theta^{3}\right)}} 14
$$

Namely, the gaps for market scales from two nations could not be remarkably large. Meanwhile, it was also known $\delta_{A B}$ and $\theta$ was positively correlated. Among them, some factors showed positive correlation to aforesaid $\delta_{1}$ and $\theta$.

Preposition 3

The gaps of market scales from two nations after FTA establishment could not be remarkably large. Also, this situation was allowed for the market scale gaps after FTA establishment. The gaps would be reduced with increasing substitute degrees. Whether member nations supported the establishment of FTA depended on substi-

\footnotetext{
${ }^{13}$ See Appendix 3.

${ }^{14}$ And $0.547723<\delta_{A B}<0.773492$ is known.
} 
tute or variance among products. When products showed substitute degrees small enough, they would express support simultaneously. However, whenever the substitute degrees of products were large enough, they showed no firmly supportive response.

For the convenience to understand aforesaid deduction, $\alpha_{B} / \alpha_{A}$ and $\theta$ were viewed as two axis. The critical values of $\delta_{1}, \delta_{A B},\left(\delta_{A B}\right)^{-1}$ and $\left(\delta_{1}\right)^{-1}$, and the correlation with $\theta$ were expressed, as Figure 1 with 4 curves $\mathrm{F}$, $\mathrm{G}, \mathrm{H}$ and $\mathrm{J}$ shown. In the figure, the range between $\mathrm{G}$ and $\mathrm{H}$ curves were subdivided into 7 zones. Among them, curve $\mathrm{F}$ and $\mathrm{J}$ corresponded by $\bar{\theta}=0.958024$, the point A and B were reflected on $\theta^{*}=0.553435$.

In contrary to the moving trend of curve $\mathrm{F}$ and $\mathrm{G}$, with $\theta$ increased, the mounting trend was slight. Meanwhile, when $\theta<\theta^{*}$, curve $\mathrm{G}$ was placed higher than curve $\mathrm{F}$. When $\theta>\theta^{*}$, curve $\mathrm{G}$ was placed lower than curve $\mathrm{F}$. The relative positions and moving trends of aforesaid curve $F$ and $G$, on one hand, they showed the condition variance whether makers and governments supported FTA. On the other hand, when $\theta<\theta^{*}$, it meant governments showed higher concern for consumer surplus. When $\theta>\theta^{*}$, governments showed higher concern to make profit. Identically, the relative positions and moving trend for both curve $\mathrm{H}$ and $\mathrm{J}$ could be known.

When $\alpha_{B} / \alpha_{A}$ fell above curve F, it meant maker 1 in the nation A would bring with increased total profit under bilateral FTA. When $\alpha_{B} / \alpha_{A}$ fell above curve G, it meant the social welfare levels in the nation A would be improved under bilateral FTA. Identically, when $\alpha_{B} / \alpha_{A}$ fell below curve J, it meant maker 2 in the nation $\mathrm{B}$ would bring with increased total profit under bilateral FTA. When $\alpha_{B} / \alpha_{A}$ fell below curve $\mathrm{H}$, it meant the social welfare in the nation $B$ would be improved. As the figure shown, when products showed lower substitute degrees (higher market divisions) located in Zone I $\left(\theta<\theta^{*}\right)$, makers from nations would support bilateral FTA. When products showed higher substitute degrees (lower market division) $\left(\theta^{*}<\theta<\bar{\theta}\right)$, then there would be three situations happening probably. If it was located within Zone II, then makers from both nations would support FTA. If it was located in Zone III, then maker 1 from the nation A would refuse bilateral FTA due to less total profit resultant. If it was locate in Zone IV, then maker 2 from the nation B would refuse bilateral FTA due to less total profit resultant. As for $\theta>\bar{\theta}$ regions, there were 3 zones divided. Among them, Zone $\mathrm{V}$ and IV were nearly the same; Zone VI and III were nearly the same. Zone VII was more special. The said zone meant market scales of both nations were quite close. When $\theta$ approximated to 1 or the substitute of goods approximated to $100 \%$, it meant makers from both nations would refuse FTA. It was known from above mention, when market scales of both nations were quite close with the difference of trade goods to a certain degree, they were just willing to establish FTA with positive support offered by makers from every nation. On the contrary, when product difference was extremely small $(\bar{\theta}<\theta<1)$ or approximated perfect substitute, makers of both nation would support FTA. As such, the results were consistent to those proposed by Levy [11] and Krishna [12].

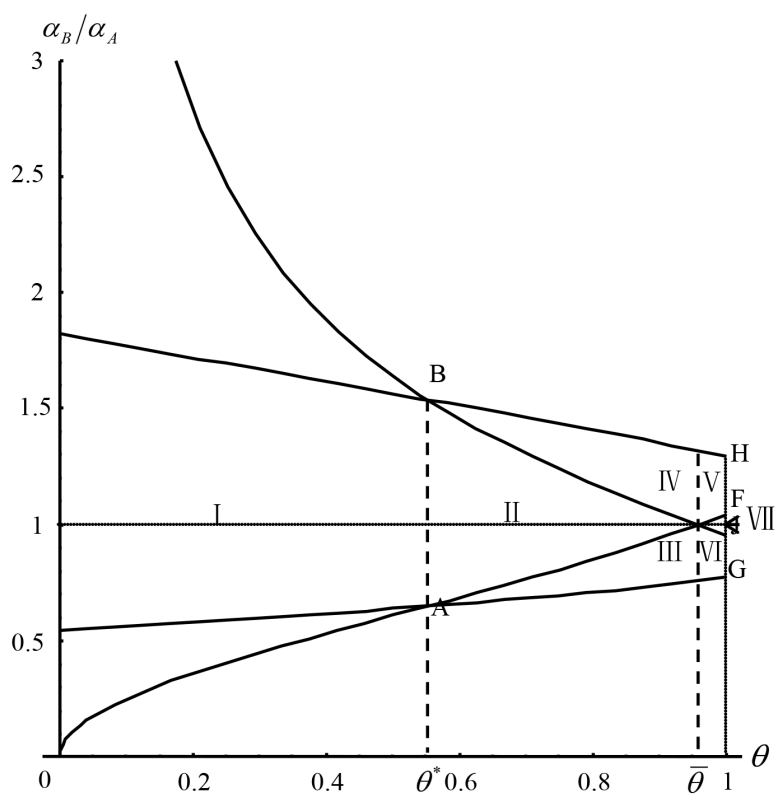

Figure 1. Maker and governments' support for FTA under various parameters of product difference. 
2) Under the condition with A-B FTA established, the nation A decided to select the nation $C$ to establish another A-C FTA. There were two FTA, namely A-B FTA and A-C FTA, co-existing simultaneously.

After A-C FTA establishment, nation B and C separately joined FTA and import tariff for those makers were:

$$
\begin{gathered}
t_{B}^{3 A B, A C}=\frac{2-\theta}{6+3 \theta-2 \theta^{2}} \alpha_{B}=t_{B}^{3 A B} \\
t_{C}^{2 A B, A C}=\frac{2-\theta}{6+3 \theta-2 \theta^{2}} \alpha_{C}<t_{C}^{2 A B}=t_{C}^{2^{*}}
\end{gathered}
$$

Identically, Equation (13) and (14) meant after FTA establishment, the import tariff on non-member nations imposed by member nations would be reduced simultaneously. Contrarily, the import tariff imposed on nations outside FTA was kept the same.

Under the condition with both A-B and A-C FTA co-existing, the social welfare levels for every nation were separately:

$$
\begin{gathered}
S W_{A}^{A B, A C}=q_{A}^{0}+\frac{(5+6 \theta) \alpha_{A}^{2}}{8 b(1+\theta)^{2}}+\frac{(3-\theta)^{2}\left(\alpha_{B}^{2}+\alpha_{C}^{2}\right)}{b\left(6+3 \theta-2 \theta^{2}\right)^{2}} \\
S W_{B}^{A B, A C}=q_{B}^{0}+\frac{\alpha_{A}^{2}}{4 b(1+\theta)^{2}}+\frac{2(2-\theta)^{2} \alpha_{C}^{2}+(8-3 \theta)\left(6+3 \theta-2 \theta^{2}\right) \alpha_{B}^{2}}{2 b\left(6+3 \theta-2 \theta^{2}\right)^{2}} \\
S W_{C}^{A B, A C}=q_{C}^{0}+\frac{\alpha_{A}^{2}}{4 b(1+\theta)^{2}}+\frac{2(2-\theta)^{2} \alpha_{B}^{2}+(8-3 \theta)\left(6+3 \theta-2 \theta^{2}\right) \alpha_{C}^{2}}{2 b\left(6+3 \theta-2 \theta^{2}\right)^{2}}
\end{gathered}
$$

was similar to the condition with A-B FTA established. A-C FTA establishment could not assured of increased social welfare of both nation A and C. Taking the nation A for example, the determinant conditions were shown as below:

$$
S W_{A}^{A B, A C}-S W_{A}^{A B}=\frac{3\left(12+6 \theta-5 \theta^{2}\right)\left(20-2 \theta-13 \theta^{2}+4 \theta^{3}\right)}{4 b\left(6+3 \theta-2 \theta^{2}\right)^{2}\left(6+2 \theta-3 \theta^{2}\right)^{2}} \alpha_{C}^{2}-\frac{(2+\theta)}{8 b(1+\theta)^{2}\left(6+3 \theta-2 \theta^{2}\right)} \alpha_{A}^{2}
$$

Through above equation, it could be deduced that the A-C FTA establishment conditions with nation A's support should be:

$$
\frac{\alpha_{C}}{\alpha_{A}} \geq \delta_{A B, A C} \text {, wherein } \delta_{A B, A C} \equiv \sqrt{\frac{(2+\theta)\left(6+3 \theta-2 \theta^{2}\right)\left(6+2 \theta-3 \theta^{2}\right)^{2}}{6(1+\theta)^{2}\left(12+6 \theta-5 \theta^{2}\right)\left(20-2 \theta-13 \theta^{2}+4 \theta^{3}\right)}}
$$

Identically, it could be deduced the A-C FTA establishment conditions with nation C's support should be:

$$
\frac{\alpha_{C}}{\alpha_{A}} \leq \delta_{A B, C A} \text {, wherein } \delta_{A B, C A} \equiv \sqrt{\frac{\left(6-2 \theta+3 \theta^{2}\right)\left(10+5 \theta-4 \theta^{2}\right)}{(3-\theta)(1+\theta)^{2}\left(6+3 \theta-2 \theta^{2}\right)}}
$$

As aforesaid, it was known that after A-B FTA establishment, A-C FTA was established with the conditions shown as below:

$$
\delta_{A B, A C} \leq \frac{\alpha_{C}}{\alpha_{A}} \leq \delta_{A B, C A}
$$

As for the change of social welfare of nation B outside the A-C FTA, they were:

$$
S W_{B}^{A B, A C}-S W_{B}^{A B}=\frac{\theta\left[(1+\theta)^{2}(2+\theta)\left(48-10 \theta-33 \theta^{2}+12 \theta^{3}\right) \alpha_{C}^{2}-\left(12+7 \theta-4 \theta^{2}\right)\left(6+2 \theta-3 \theta^{2}\right)^{2} \alpha_{A}^{2}\right]}{4 b(1+\theta)^{2}\left(6+3 \theta-2 \theta^{2}\right)^{2}\left(6+2 \theta-3 \theta^{2}\right)^{2}}
$$

Based on above equation, it was deduced that the conditions for improved social welfare of nation B after 
A-C FTA establishment were:

$$
\frac{\alpha_{C}}{\alpha_{A}} \geq \delta_{-B} \text {, wherein } \delta_{-B} \equiv \sqrt{\frac{\left(12+7 \theta-4 \theta^{2}\right)\left(6+2 \theta-3 \theta^{2}\right)^{2}}{(1+\theta)^{2}(2+\theta)\left(48-10 \theta-33 \theta^{2}+12 \theta^{3}\right)}}
$$

The correlation among three parameters, $\delta_{A B, A C}, \delta_{A B, C A}$ and $\delta_{-B}$, and $\theta$ were illustrated in Figure 2.

In Figure 2, line $\mathrm{L}, \mathrm{M}$ and $\mathrm{N}$ were respectively designated as the correlation among three parameters $\delta_{A B, A C}$, $\delta_{A B, C A}$ and $\delta_{-B}$, and $\theta$. It was known that all three parameters showed negative correlation to $\theta$. It was also known and noteworthy that with $\theta$ increased, line $\mathrm{L}$ and line $\mathrm{G}$ in Figure 1 were not moving consistently. It meant whenever the nation A government collaborated with nation $C$ to establish FTA, the demand on market scale in the nation $\mathrm{C}$ would be reduced with $\theta$ increased. It could be explained as below. After A-C FTA establishment, as for the result of both nation $\mathrm{C}$ and $\mathrm{B}$ to share markets in the nation $\mathrm{A}$, the influence on nation $\mathrm{B}$ would be larger than that on nation A. Also, the said influence would be increased with $\theta$ increased remarkably more and more. As such, although makers in the nation A were also affected, consumers from nation A would be benefited much more from free market competition. Thus, the consideration for nation A to accept the conditions for FTA establishment with the nation $\mathrm{C}$ would be more graced (in view of market scales in the nation C).

When $\alpha_{C} / \alpha_{A}$ ranged between the region above line $\mathrm{L}$ and below line $\mathrm{M}$ with nation $\mathrm{A}$ and $\mathrm{C}$ co-existing under A-B FTA, A-C FTA establishment would bring with increased social welfare for both nations. It was exactly the condition to establish A-C FTA. Meanwhile, under the condition with A-C FTA establishment, the social welfare in the nation $\mathrm{B}$ was range below line $\mathrm{N}$ for all of them in the said region. Thus, under existing $\mathrm{A}-\mathrm{B}$ FTA, the social welfare in the nation B would be definitely reduced when A-C FTA was established. It was testified that A-C FTA establishment did consist to the relevant baselines and norms proposed by Kemp and Wan, Krishna and Panagariya, together with GATT/WTO. The welfare of nation B would be damaged due A-C FTA establishment. It was under a condition with both A-B and A-C FTA co-existing, the nation C and B could share markets in the nation A of no tariff bound. Thus, the welfare obtained by nation $\mathrm{C}$ was increased. As such, although the nation $\mathrm{B}$ was affected by the trade expansion effect from tariff-deduction from the nation $\mathrm{C}$, it was still unavailable to compensate the welfare loss for the markets in nation A commonly shared with nation $\mathrm{C}^{15}$. Namely, with FTA expanded, regional integration would do damage to multilateralism.

To sum up, after the discussion this section, it was known that it was aimed to reach the globally single FTA through regional FTA, it would be impossible unless there were other compensating mechanisms available. Following that, the discussion was continued to focus on the conditions for globally single FTA.

\section{Preposition 4}

Under existing FTA, the conditions for a certain member nation and other nations outside FTA to establish bilateral FTA were described as below. The market scale gaps between two nations should never be remarkable. Meanwhile, the said new FTA would be refused by other member nations belonging to the original FTA.

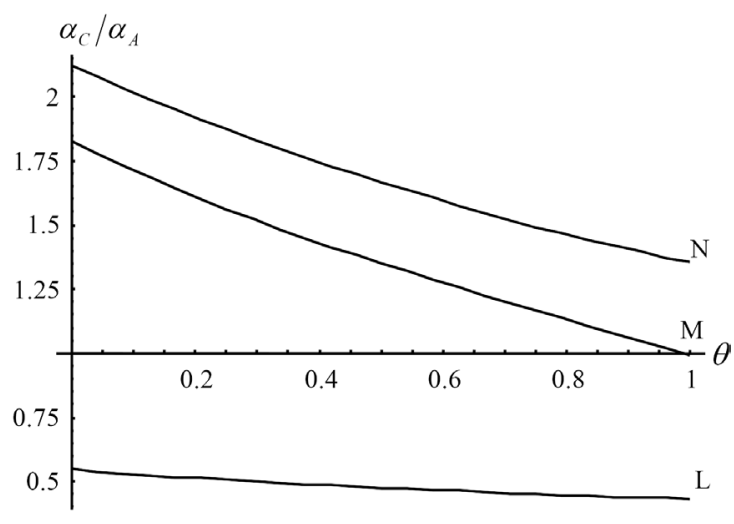

Figure 2. The parameter conditions of A-C FTA establishment.

\footnotetext{
${ }^{15}$ Identically, if there was a type of transfer mechanism existing in cross-nation welfare, whenever market scales in nation $\mathrm{C}$ was large enough, the government of nation A could persuade nation B to agree with A-C FTA agreement by compensating nation B.
} 
3) The conditions to establish a globally single FTA

There were two situations available to discuss the issues for the establishment of a globally single FTA.

a) It started from nothing till a globally single FTA was well established (A-B-C).

b) The establishment was operated through bilateral effort (A-B) to multilateral effort (A-B-C).

Under the condition with a globally single FTA established, all tariff policies would become tariff-free. And then, the welfare levels for every nation were shown as below:

$$
S W_{i}^{F T A}=q_{i}^{0}+\frac{(5+6 \theta) \alpha_{i}^{2}+2 \sum \alpha_{-i}^{2}}{8 b(1+\theta)^{2}}, \quad i=\mathrm{A}, \mathrm{B}, \mathrm{C}
$$

a) It started from nothing till a globally single FTA was well established (A-B-C).

The FTA established in a one-run effort would not improve welfare for every nation certainly with the determinant conditions as below:

$$
S W_{i}^{F T A}-S W_{i}^{*}=\frac{2(2+\theta)\left(10+3 \theta-6 \theta^{2}\right) \sum \alpha_{-i}^{2}-(2+\theta)^{2}\left(6+2 \theta-3 \theta^{2}\right) \alpha_{i}^{2}}{8 b(1+\theta)^{2}\left(6+2 \theta-3 \theta^{2}\right)^{2}}, i=\mathrm{A}, \mathrm{B}, \mathrm{C}
$$

Taking nation A for example, it was known from above equation. The conditions for nation A to join FTA were:

$$
\frac{\sqrt{\left(\sum \alpha_{-A}^{2}\right)}}{\alpha_{A}}=\left[\sum_{-A}\left(\frac{\alpha_{-A}}{\alpha_{A}}\right)^{2}\right]^{\frac{1}{2}} \geq \delta_{F T A}^{1} \text {, where } \delta_{F T A}^{1} \equiv \sqrt{\frac{(2+\theta)\left(6+2 \theta-3 \theta^{2}\right)}{2\left(10+3 \theta-6 \theta^{2}\right)}} 16
$$

On one hand, it was known from above equation that if the market scales of a nation were not remarkably large just similar to those proportion square roots in other nations, or the market scales of other nations were large enough similar to the proportion square root of that of a nation, then the said nation would be highly willing to join FTA and further to establish a globally single FTA. On the other hand, when the markets of a nation were increasingly large, the said nation would show higher resistance to join FTA and it was because the said nation shared the global interest with other nations with little attraction available. Thus, it showed less inclination to open its own markets of no tariff imposed. Namely, the larger market scales the nations owned, the less supportive intention the nations posed toward a FTA establishment ${ }^{17}$.

b) The establishment was operated through bilateral effort (A-B) to multilateral effort (A-B-C).

From existing A-B FTA to a globally single FTA, the welfare change for every nation was separately:

$$
\begin{gathered}
\Delta S W_{i}=\frac{-(2+\theta) \alpha_{i}^{2}}{8 b(1+\theta)^{2}(6+3 \theta-2 \theta)}+\frac{-\theta\left(12+7 \theta-4 \theta^{2}\right) \alpha_{-i}^{2}}{4 b(1+\theta)^{2}\left(6+3 \theta-2 \theta^{2}\right)^{2}}+\frac{(2+\theta)\left(10+3 \theta-6 \theta^{2}\right) \alpha_{C}^{2}}{4 b(1+\theta)^{2}\left(6+2 \theta-3 \theta^{2}\right)^{2}}, \quad i=\mathrm{A}, \mathrm{B} \\
\Delta S W_{C}=\frac{(2+\theta)\left(10+5 \theta-4 \theta^{2}\right)\left(\alpha_{A}^{2}+\alpha_{B}^{2}\right)}{4 b(1+\theta)^{2}\left(6+3 \theta-2 \theta^{2}\right)^{2}}-\frac{(2+\theta)^{2} \alpha_{C}^{2}}{8 b(1+\theta)^{2}\left(6+2 \theta-3 \theta^{2}\right)}
\end{gathered}
$$

It was known from Equation (21), whenever the market scales in nation C was larger, both nation A and B would receive more maker profit and social welfare. Thus, both nations showed high willing to bear the loss of social welfare when markets of both nations were opened. They were willing to collaborate with nation $\mathrm{C}$ to establish a globally single FTA. The condition for nation C willing to join a globally single FTA depended on the market scales from other nations, with the said conditions described as below:

$$
\frac{\sqrt{\left(\sum \alpha_{-C}^{2}\right)}}{\alpha_{C}} \geq \delta_{\text {FTA }}^{2} \text {, where } \delta_{F T A}^{2} \equiv{\sqrt{\frac{(2+\theta)\left(6+3 \theta-\theta^{2}\right)^{2}}{2\left(6+2 \theta-3 \theta^{2}\right)\left(10+5 \theta-4 \theta^{2}\right)}}}_{18}^{18}
$$

\footnotetext{
${ }^{16}$ And also known that $0.774597<\delta_{\text {FTA }}^{1}<1.0351$.

${ }^{17}$ If there was a transfer mechanism for welfare among various nations, it could be assumed of better welfare after joining the globally single FTA. The conditions of Equation (19) became: $\left(28+2 \theta-20 \theta^{2}+3 \theta^{3}\right)(2+\theta)\left(\alpha_{A}^{2}+\alpha_{B}^{2}+\alpha_{C}^{2}\right) / 8 b(1+\theta)^{2}\left(6+2 \theta-3 \theta^{2}\right)^{2}$ was always larger than 0 . It meant after the establishment of a globally single FTA was done, the total global welfare would be increased certainly.

${ }^{18}$ And also known that $0.774597<\delta_{\text {FTA }}^{2}<1.15601$.
} 
In comparison with Equation (20) and (22), the influence on original alliance nations (nation C) for the establishment of a globally single FTA formed by nations from two different regions. The correlation between two parameters $\delta_{F T A}^{1}$ and $\delta_{F T A}^{2}$, together with $\theta$, were shown as Figure 3.

In Figure 3, the line R and respectively showed the correlation between two parameters $\delta_{F T A}^{1}$ and $\delta_{F T A}^{2}$, together with $\theta$. It was known that both were positively correlated to $\theta . \quad \delta_{\text {FTA }}^{1}<\delta_{\text {FTA }}^{2}$ was also known. When it was located above line S, no matter whether there was a A-B FTA existing or not, nation C to join the globally single FTA would bring with increased social welfare. When it was located between the region above line $\mathrm{R}$ and below line S, under the existing A-B FTA, the welfare of nation C would be reduced after joining a globally single FTA. However, on the other hand, if nation $C$ spent one-run effort to join a globally single FTA, its welfare would be improved. In other words, the idea to establish a globally single FTA by spending one-run effort, it would succeed much easier.

\section{Preposition 5}

When the market scale square for every nation was not remarkably large when compared with the market scale square from other nations, the establishment for a globally single FTA would be reachable conditionally. When the gradual expansion for currently existing FTA compared with initial effort to establish a globally single FTA, the former would succeed much easier.

Finally, in view of the makers from existing preferential bilateral agreement alliance, we further discuss whether it would be possible for makers' refusal against the liberalization for multilateral trade through lobbying.

Under the existing A-B FTA, the total profit of nation A was:

$$
\pi_{1}^{A B}=\frac{(4-3 \theta)^{2}\left(6+3 \theta-2 \theta^{2}\right)^{2} \alpha_{C}^{2}+4(3-\theta)^{2}\left(6+2 \theta-3 \theta^{2}\right)^{2}\left(\alpha_{A}^{2}+\alpha_{B}^{2}\right)}{b\left[2\left(6+2 \theta-3 \theta^{2}\right)\left(6+3 \theta-2 \theta^{2}\right)\right]^{2}}
$$

Under a globally single FTA, the total profit of nation A was:

$$
\pi_{1}^{F T A}=\frac{\alpha_{A}^{2}+\alpha_{B}^{2}+\alpha_{C}^{2}}{4 b(1+\theta)^{2}}
$$

The profit difference was:

$$
\pi_{1}^{F T A}-\pi_{1}^{A B}=\frac{(2+\theta)\left(10+3 \theta-6 \theta^{2}\right)\left(6+3 \theta-2 \theta^{2}\right)^{2} \alpha_{C}^{2}-\theta\left(12+7 \theta-4 \theta^{2}\right)\left(6+2 \theta-3 \theta^{2}\right)^{2}\left(\alpha_{A}^{2}+\alpha_{B}^{2}\right)}{4 b(1+\theta)^{2}\left(6+2 \theta-3 \theta^{2}\right)^{2}\left(6+3 \theta-2 \theta^{2}\right)^{2}}
$$

Known from above mention, with the goal for maximized social welfare for nation $\mathrm{A}$, to the conditions to join a globally single FTA were $\alpha_{C}^{2} \geq \delta_{F T A}^{1} \alpha_{A}^{2}-\alpha_{B}^{2}$; Based on equation (23), it was deduced that under existing A-B FTA, the conditions for nation A to refuse against a globally single FTA were:

$$
\alpha_{C}^{2}<\delta_{2}\left(\alpha_{A}^{2}+\alpha_{B}^{2}\right) \text {, wherein } \delta_{2} \equiv \theta\left(12+7 \theta-4 \theta^{2}\right)\left(6+2 \theta-3 \theta^{2}\right)^{2} /(2+\theta)\left(10+3 \theta-6 \theta^{2}\right)\left(6+3 \theta-2 \theta^{2}\right)^{2}
$$

Thus, it was known that makers in nation would refuse against the establishment for a globally single FTA by lobbying. The conditions to stop nation A governments from joining it were: $\left(\delta_{F T A}^{1} \alpha_{A}^{2}-\alpha_{B}^{2}\right) \leq \alpha_{C}^{2}<\delta_{2}\left(\alpha_{A}^{2}+\alpha_{B}^{2}\right)$.

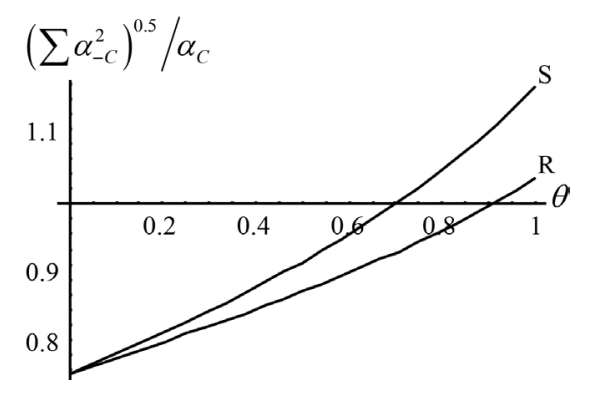

Figure 3. The parameter conditions for nation $\mathrm{C}$ to join a globally single FTA. 
As such, it could be deduced the required conditions for establishment were: $\alpha_{B} / \alpha_{A}>\delta_{3} \equiv \sqrt{\left(\delta_{F T A}^{1}-\delta_{2}\right) /\left(\delta_{2}+1\right)}$.

The correlation between $\delta_{3}$ and $\theta$ was illustrated as the line $\mathrm{T}$ in Figure 4. In Figure 4, the region above line $\mathrm{T}$ meant the required conditions for makers in nation A would refuse against and stop the government from the establishment of a globally single FTA by lobbying. It could be further known from Figure 4. When market scales in nation $\mathrm{B}$ approximated to those in nation $\mathrm{A}$, makers in nation A would refuse against multilateral free trade through lobbying. Contrarily, when market scales in nation B (compared with nation A) were small, makers in nation A show higher willing to join multilateral free trade. Based on above mention, it was known that under the premise with bilateral preferential trade agreement, local makers would not should absolute refusal against the establishment for multilateral free trade. The said results were not consistent to the conclusions reached by Levy [11] and Krishna [12] when $\theta=1$ or perfect substitute goods were existing.

\section{Preposition 6}

Under the premise with bilateral trade agreement, local makers would show no absolute refusal against multilateral free trade. It actually depended on the comparative sizes for the market scales respectively in member nations, potential member nations and local regions. When the market scales of FTA member nations were increasingly large local makers would probably refuse against multilateral free trade through lobbying. Contrarily, when the market scales of FTA member nations were increasingly small, local makers would probably enhance their support for multilateral free trade.

\section{The Strategy Analysis for Selecting FTA Partners}

In this section, based on aforesaid FTA establishment conditions, under various designs with different national market scales, the strategies to select FTA partners were discussed. Herein, to simplify the explanation, let $\alpha_{A} \geq \alpha_{B} \geq \alpha_{C}$, it meant nation A was a big nation but nation B was a medium nation in size. Nation C was small nation. It was also assumed that $\alpha_{B} \equiv h \alpha_{A}, \alpha_{C} \equiv k \alpha_{A}$ and $0<k \leq h \leq 1$. In Figure 5, the zone above line L meant the conditions for nation A, under the existing A-B FTA (or A-C) to further collaborate with nation C (or B) for bilateral FTA establishment. The zone above line G meant the conditions for nation A to establish a bilateral FTA but no joining FTA before. The zone above line $\mathrm{M}$ meant the conditions for nation to collaborate with nation B (or C) for A-B (or A-C) FTA establishment within nation A under existing B-C FTA. It was also known that $L<G<M$. As below described, the conditions based on (1) and (2) listed in section 3 would be discussed respectively.

Under the situation listed in (1) of section 3, it was known from Figure 5. When nation A showed its aggressive attitude (no FTA existing), the initial selection for FTA partners (the zone about line G) compared with nation A under existing FTA to establish new alliance (the zone above line L) were required for conditions with higher levels. Namely, nation A would firstly collaborate with nation B of similar market scales to establish bilateral FTA. Secondly, the collaboration with nation C for bilateral FTA establishment was just taken into consideration. When nation A was passively invited for alliance (under existing B-C FTA), if it collaborated with nations never joining any FTA before to establish a new FTA (the zone above line G), compared with FTA establishment in collaboration with nation A, an existing FTA member (the zone above line M), relevant conditions were looser. It meant nation A was aggressively willing to dominate the FTA alliance. It was not passively selected by other FTA member nations for alliance participation. Namely, it was initially known that the strategies

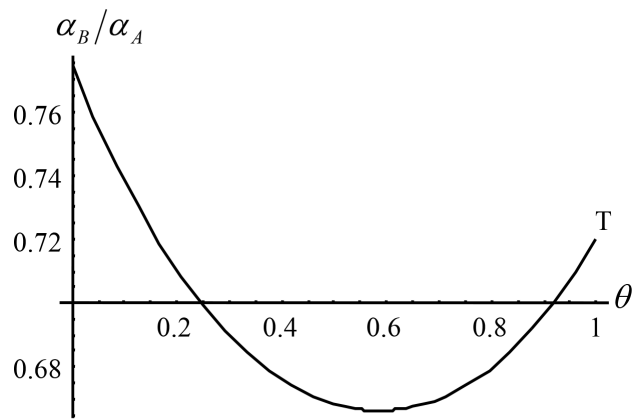

Figure 4. The conditions for makers in nation A to refuse against multilateral free trade. 


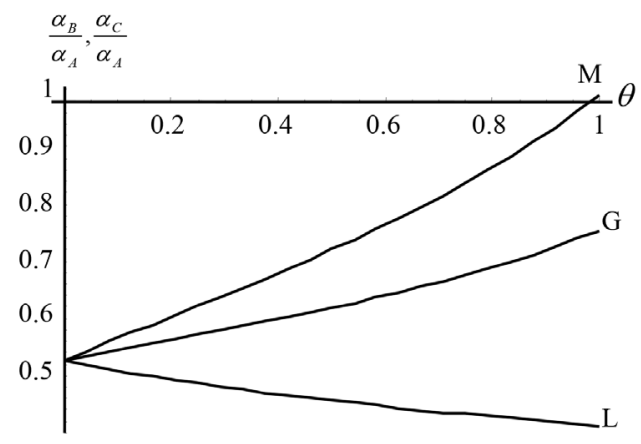

Figure 5. The strategy conditions for nation A (a big nation) to select FTA partners.

for nation A to select FTA partners were described as below. When B-C FTA did not exist with small gaps on market scales from various nations, nation would firstly collaborate with nation $\mathrm{B}$ and then invited nation $\mathrm{C}$ for alliance linkage. If under B-C FTA, nation A would incline to form an alliance with the medium nations in size (nation B).

Under $\alpha_{A} \geq \alpha_{B} \geq \alpha_{C}$, the alliance strategies of a big nation (nation A) could be subdivided into below situations for analysis:

1) $k \geq M$ : Nation A could aggressively or passively form an alliance with any nations.

2) $G \leq k<M \leq h$ : Nation A could aggressively form an alliance with any nation, but passively to form an alliance with nation $\mathrm{B}$.

3) $G \leq k \leq h<M$ : Nation A could aggressively form an alliance with any nation, but passively form no alliance.

4) $L \leq k<G<M \leq h$ : Nation A aggressively forms an alliance with Nation B and then Nation C, but passively forms an alliance with Nation B only.

5) $L \leq k<G \leq h<M$ : Nation A aggressively forms an alliance with Nation B and then Nation C, but passively forms no alliance.

6) $h<G$ : Nation A however aggressively or passively forms no alliances.

Nation A could aggressively or passively form an alliance with any nation or passively refuse any alliance.

Thereafter, under $\alpha_{A} \geq \alpha_{B} \geq \alpha_{C}$, the alliance strategies for medium nations in size (nation $\mathrm{B}$ ) could be further subdivided as below for analysis:

1) $(k / h) \geq M$ : Nation B could aggressively or passively form an alliance with any nation.

2) $G \leq(k / h)<M$ : Nation B could aggressively form an alliance with any nation in any order, but passively form an alliance with nation $\mathrm{A}$.

3) $L \leq(k / h)<G$ : Nation B aggressively and firstly forms an alliance with nation A and then nation C, but passively forms an alliance with nation $A$.

4) $(k / h)<L$ : Nation B could aggressively or passively form an alliance with nation A only.

Finally, the alliance strategies for small nations (nation C) would show their absolutely high willing to form an alliance with any nations however aggressively or passively.

Under the situation mentioned in (2), section 3, the conditions of Equation (16) would be satisfied automatically. Just in view of Equation (15) (namely in view of the conditions of line L), it meant markets in nation C should be large enough to attract nation A for alliance. Otherwise, if markets in nation A were quite large, nation A would show no willing to establish A-C FTA with nation C.

Under existing A-B FTA, the probabilities for nation C outside FTA and nation B to establish FTA were discussed. As such, nation $C$ was willing to form an alliance with nation B. However, nation A would show its refusal against the B-C FTA establishment. The attitude of nation B depended on the menace caused by nation A. If the premise to form an alliance with nation B was required to abort A-B FTA agreement, nation B would certainly refuse due remarkable loss. Except by means of multilateral negotiation, nation A would not suffer any loss due co-existing A-B and B-C FTA. Thus, nation B could not form an alliance with nation C alone. Finally, small nations were trapped in a structure unavailable to join $(\mathrm{AB}, \mathrm{AC})$ or $(\mathrm{AB}, \mathrm{BC})$ alliances.

It was known from above mention that under the premise with the goal to maximize social welfare locally for 
this research model, the strategies for big nations were described as below. When they were selecting any partners for bilateral FTA, they would firstly select big nations and then select small nations for alliance probably. When they were selecting existent FTA members for alliance partners, they would either select big nations for alliance or no partner for alliance at all. The strategies for medium nations in size were described as below. Under any condition, they would firstly form an alliance with big nations. The alliance strategies for small nations would show no refusal but try any possible effort to form an alliance with any nation.

\section{Preposition 7}

The possible alliance strategies for big nations to select FTA partners were described as below. When they were selecting nations of no joining FTA alliance before, they would like to form an alliance with medium nations or small nations and the medium nations would come earlier than the small ones. When they were selecting the partners from existing FTA members, they either formed an alliance with medium nations or no partner for alliance at all. The alliance strategies for medium nations were described as below. Under any situation, they would firstly form an alliance with big nations. The alliance strategies for small nations were that they would try any possible effort to form an alliance with any nation.

\section{Conclusion and Suggestion}

After aforesaid analysis, some conclusions could be reachable in this article: 1) The optimal import tariff locally would cause the same influence on makers from various nations. The foreign market scales were positively correlated to those of local markets. However, the correlation between local and foreign goods or substitute goods $(\theta)$ was uncertain. When $\theta$ was relatively large, the optimal import tariff was negatively correlated to $\theta$. When $\theta$ was relatively small, the optimal import tariff was positively correlated to $\theta$. 2) After FTA establishment for both nations, the tariff imposed on non-member nations would be reduced simultaneously. As such, it would not only increase the import volume from member nations but also increase the import volume from non-member nations. Although the makers from member nations reduced their output in local markets, the export volume of the said member nations was increased contrarily. Thus, after FTA establishment, the total output of local makers would probably increase but not reduce. 3) The condition for FTA establishment was exactly no remarkable gaps allowed on market scales between two nations. The said allowable condition for market scale gaps happening to FTA establishment would be reduced with substitute degrees for products increased. Whether the member nations are willing to support the establishment of the FTA depended on the substitute goods and the difference degrees of products. Whenever the substitute degrees for products were small enough, they would support simultaneously. Whenever the substitute degrees were remarkable, they showed no absolute support. 4) Under existing FTA, the conditions for a given member nation to establish a new FTA with a nation outside FTA were described as below. FTA establishment was only available for no remarkable market scale gaps happening to both nations. Meanwhile, the said newly established FTA would be refused by other member nations in the original FTA areas. 5) Compared with the square sum of market scales from other nations globally, when the square of market scales for every nation was not remarkably large, there would be a globally single FTA by spending one-run effort. Compared with the FTA gradually formed, a globally single FTA by spending one-run effort could be reachable much easier. 6) Under the premise with bilateral preferential trade agreement locally, local makers showed no absolute refusal to multilateral free trade. It actually depended on the market scales of member nations and potential member nations when compared with local market scales. The larger the market scales of existing FTA member nations they were, the more lobbying effort made by local makers with refusal to multilateral free trade there would be. On the contrary, the smaller the market scales of FTA member nations they were, the more support from local makers for multilateral free trade there would be. 7) The possible strategies for big nations to select FTA partners were described as below. When they were selecting the nations of no joining bilateral FTA before, they would like to form an alliance with medium nations firstly and small nations later. When they were selecting partners from existing FTA member nations, they either selected medium nations for alliance or no partner at all. The alliance strategies for medium nations were described as below. Under any situation, they firstly formed an alliance with big nations. The alliance strategies for small nations were the fact that they would try any possible effort to form an alliance with any nation.

In this article, the establishment for a new FTA or joining existent FTA, together with the issues the conflict happening to bilateralism and multilateralism was discussed herein. Also, based on relevant hypothesis conditions, aforesaid conclusions were reachable. Among them, to highlight the trade formation theory and strategic 
trade policies based on market structural difference yet not on technical level gaps, not only all production cost for every nation was conditioned as consistent, but also inconsistent production technique gaps for every nation was ignored and the resale behaviors were also forbidden among all nations. Thus, the subsequent research for the issue about "On Selecting Strategies of FTA Partners" seemed to reach a fact that the factors of technical gaps on production and the difference on market structures could be taken into the modal design for consideration available for further research on the said issue.

\section{References}

[1] Viner, J. (1950) The Customs Union Issue. Carnegie Endowment for International Peace, New York.

[2] Kemp, M.C. and Wan Jr., H. (1976) An Elementary Proposition Concerning the Formation of Customs Unions. In: Kemp, M., Ed., Three Topics in the Theory of International Trade: Distribution, Welfare, and Uncertainty, North Holland, Amsterdam. http://dx.doi.org/10.1016/0022-1996(76)90025-8

[3] Krishna, P. and Panagariya, A. (2002) On Necessarily Welfare-Enhancing Free Trade Areas. Journal of International Economics, 57, 353-367. http://dx.doi.org/10.1016/S0022-1996(01)00152-0

[4] Kennan, J. and Riezman, R. (1990) Optimal Tariff Equilibria with Customs Unions. Canadian Journal of Economics, 23, 70-83. http://dx.doi.org/10.2307/135520

[5] Richardson, M. (1993) Endogenous Protection and Trade Diversion. Journal of International Economics, 34, 309-324. http://dx.doi.org/10.1016/0022-1996(93)90052-Y

[6] Bagwell, K. and Staiger, R. (1999) Regionalism and Multilateral Tariff Cooperation. In: Piggott, J. and Woodland, A., Eds., International Trade Policy and the Pacific Rim, Macmillan: London. http://dx.doi.org/10.1007/978-1-349-14543-0_7

[7] Ornelas, E. (2002) Endogenously Determined Free Trade Agreements and the Multilateral Trading System. Mimeo, University of Georgia.

[8] Krugman, P. (1991) Increasing Returns and Economic Geography. The Journal of Political Economy, 99, 483-499. http://dx.doi.org/10.1086/261763

[9] Grossman, G. and Helpman, E. (1995) The Politics of Free Trade Agreement. The American Economic Review, 85, 667-690.

[10] Panagariya, A. and Findlay, R. (1996) A Political Economy Analysis of Free Trade Areas and Customs Unions. In: Feenstra, R., Irwin, D. and Grossman, G., Eds., The Political Economy of Trade Reform, MIT Press, Cambridge, MA.

[11] Levy, P.I. (1997) A Political-Economics Analysis of Free-Trade Agreements. American Economic Review, 87, 506519.

[12] Krishna, P. (1998) Regionalism and Multilateralism: A Political Economy Approach. The Quarterly Journal of Economics, 113, 227-252. http://dx.doi.org/10.1162/00335539851144162

[13] Bond, E.W., Riezman, G.R. and Syropoulos, C. (2004) A Strategic and Welfare Theoretic Analysis of Free Trade Areas. Journal of International Economics, 64, 1-27. http://dx.doi.org/10.1016/S0022-1996(03)00078-3

[14] Ornelas, E. (2005) Trade Creation Free Trade Areas and the Undermining of Multilateralism. European Economic Review, 49, 1717-1735. http://dx.doi.org/10.1016/j.euroecorev.2004.03.010

[15] Kiyono, K. (2009) Incentives towards Economic Integration as the Second-Best Tariff Policy. Asia-Pacific Journal of Accounting \& Economics, 16, 19-48. http://dx.doi.org/10.1080/16081625.2009.9720828

[16] Krugman, P. (1993) The Narrow and Broad Arguments for Free Trade. The American Economic Review, 83, 362-366.

[17] Brander, J. and Krugman, P. (1983) A Reciprocal Dumping Model of International Trade. Journal of International Economics, 15, 313-321. http://dx.doi.org/10.1016/S0022-1996(83)80008-7

[18] Riezman, R. (1979) A 3 × 3 Model of Customs Unions. Journal of International Economics, 9, 341-354. http://dx.doi.org/10.1016/0022-1996(79)90030-8

[19] Hsu, C.C., Tsai, C.S. Lee, R.Y. and Hwang, C.S. (2009) The Attribute of the Tradable Good and the Competitive Equilibrium of Trade Policy. Nankai Economic Studies, 146, 3-14.

[20] Dixit, A. (1984) International Trade Policy for Oligopolistic Industries. Economic Journal, 94, 1-16. http://dx.doi.org/10.2307/2232651

[21] Yang, Y.P. and Hwang, H. (2005) Optimal Export Policy and Competition Strategies. Journal of Social Sciences and Philosophy, 17, 761-784.

[22] Cable, J., Carruth, A. and Dixit, A. (1994) Oligopoly and Welfare. In: Cable, J., Ed., Current Issue in Industrial Economics, Macmillan Press, London, 81-104. http://dx.doi.org/10.1007/978-1-349-23154-6_5 
C.-C. Hsu

Appendix 1

The market equilibrium price, quantity and social welfare level under the original presence of tariff barriers in country A and country B are:

Country B

$$
\begin{gathered}
q_{B}^{1}=\frac{\alpha_{B}}{2 b(1+\theta)}+\frac{\theta\left(t_{B}^{1}+t_{B}^{3}\right)-2(1+\theta) t_{B}^{1}}{2 b(1+\theta)(2-\theta)} \\
q_{B}^{2}=\frac{\alpha_{B}}{2 b(1+\theta)}+\frac{\theta\left(t_{B}^{1}+t_{B}^{3}\right)}{2 b(1+\theta)(2-\theta)} \\
q_{B}^{3}=\frac{\alpha_{B}}{2 b(1+\theta)}+\frac{\theta\left(t_{B}^{1}+t_{B}^{3}\right)-2(1+\theta) t_{B}^{3}}{2 b(1+\theta)(2-\theta)} \\
Q_{B}=q_{B}^{2}+\theta q_{B}^{1}+\theta q_{B}^{3}=\frac{(1+2 \theta) \alpha_{B}-\left(t_{B}^{1}+t_{B}^{3}\right)}{2 b(1+\theta)} \\
P_{B}^{1}=\frac{\alpha_{B}}{2(1+\theta)}+c+\frac{\theta\left(t_{B}^{1}+t_{B}^{3}\right)+2\left(1-\theta^{2}\right) t_{B}^{1}}{2(1+\theta)(2-\theta)} \\
P_{B}^{2}=\frac{\alpha_{B}}{2(1+\theta)}+c+\frac{\theta\left(t_{B}^{1}+t_{B}^{3}\right)}{2(1+\theta)(2-\theta)} \\
P_{B}^{3}=\frac{\alpha_{B}}{2(1+\theta)}+c+\frac{\theta\left(t_{B}^{1}+t_{B}^{3}\right)+2\left(1-\theta^{2}\right) t_{B}^{3}}{2(1+\theta)(2-\theta)} \\
\left.+2 \theta^{3}\left[3 \alpha_{B}^{2}+\left(t_{B}^{1}-t_{B}^{3}\right)^{2}\right]\right\} \\
+W_{B}=q_{B}^{0}+\frac{\pi_{B}^{m}=b\left(q_{B}^{m}\right)^{2}, \quad m=1,2,3}{8 b(2-\theta)^{2}(1+\theta)^{2}} *\left\{4\left[5 \alpha_{B}^{2}+2\left(t_{B}^{1}+t_{B}^{3}\right) \alpha_{B}-3\left(t_{B}^{12}+t_{B}^{32}\right)+2\left(\alpha_{A}-t_{A}^{2}\right)^{2}+2\left(\alpha_{C}-t_{C}^{2}\right)^{2}\right]\right. \\
+4 \theta\left[\alpha_{B}^{2}-3\left(t_{B}^{12}+t_{B}^{32}\right)+4 t_{B}^{1} t_{B}^{3}-2\left(\alpha_{A}-t_{A}^{2}\right)\left(\alpha_{A}+t_{A}^{2}-t_{A}^{3}\right)-2\left(\alpha_{C}-t_{C}^{2}\right)\left(\alpha_{C}+t_{C}^{2}-t_{C}^{1}\right)\right] \\
\left.\left.+\theta_{B}^{32}\right)+10 t_{B}^{1} t_{B}^{3}-2 \alpha_{B}\left(t_{B}^{1}+t_{B}^{3}\right)-19 \alpha_{B}^{2}+2\left(\alpha_{A}+t_{A}^{2}-t_{A}^{3}\right)^{2}+2\left(\alpha_{C}+t_{C}^{2}-t_{C}^{1}\right)^{2}\right]
\end{gathered}
$$

Country C

$$
\begin{gathered}
q_{C}^{1}=\frac{\alpha_{C}}{2 b(1+\theta)}+\frac{\theta\left(t_{C}^{1}+t_{C}^{2}\right)-2(1+\theta) t_{C}^{1}}{2 b(1+\theta)(2-\theta)} \\
q_{C}^{2}=\frac{\alpha_{C}}{2 b(1+\theta)}+\frac{\theta\left(t_{C}^{1}+t_{C}^{2}\right)-2(1+\theta) t_{C}^{2}}{2 b(1+\theta)(2-\theta)} \\
q_{C}^{3}=\frac{\alpha_{C}}{2 b(1+\theta)}+\frac{\theta\left(t_{C}^{1}+t_{C}^{2}\right)}{2 b(1+\theta)(2-\theta)} \\
Q_{C}=q_{C}^{3}+\theta q_{C}^{1}+\theta q_{C}^{2}=\frac{(1+\theta) \alpha_{C}-\left(t_{C}^{1}+t_{C}^{2}\right)}{2 b(1+\theta)}
\end{gathered}
$$

694 


$$
\begin{gathered}
P_{C}^{1}=\frac{\alpha_{C}}{2(1+\theta)}+c+\frac{\theta\left(t_{C}^{1}+t_{C}^{2}\right)+2(1-\theta) t_{C}^{1}}{2(1+\theta)(2-\theta)} \\
P_{C}^{2}=\frac{\alpha_{C}}{2(1+\theta)}+c+\frac{\theta\left(t_{C}^{1}+t_{C}^{2}\right)+2(1-\theta) t_{C}^{2}}{2(1+\theta)(2-\theta)} \\
P_{C}^{3}=\frac{\alpha_{C}}{2(1+\theta)}+c+\frac{\theta\left(t_{C}^{1}+t_{C}^{2}\right)}{2(1+\theta)(2-\theta)} \\
S W_{C}=q_{C}^{0}+\frac{1}{8 b(2-\theta)^{2}(1+\theta)^{2}} *\left\{4\left[5 \alpha_{C}^{2}+2\left(t_{C}^{1}+t_{C}^{2}\right) \alpha_{C}-3\left(t_{C}^{12}+t_{C}^{22}\right)+2\left(\alpha_{A}-t_{A}^{3}\right)^{2}+2\left(\alpha_{B}-t_{B}^{3}\right)^{2}\right]\right. \\
+4 \theta\left[\alpha_{C}^{2}-3\left(t_{C}^{12}+t_{C}^{22}\right)+4 t_{C}^{1} t_{C}^{2}-2\left(\alpha_{A}-t_{A}^{3}\right)\left(\alpha_{A}+t_{A}^{3}-t_{A}^{2}\right)-2\left(\alpha_{B}-t_{B}^{3}\right)\left(\alpha_{B}+t_{B}^{3}-t_{B}^{1}\right)\right] \\
+\theta^{2}\left[\left(t_{C}^{12}+t_{C}^{22}\right)+10 t_{C}^{1} t_{C}^{2}-2 \alpha_{C}\left(t_{C}^{1}+t_{C}^{2}\right)-19 \alpha_{C}^{2}+2\left(\alpha_{A}+t_{A}^{3}-t_{A}^{2}\right)^{2}+2\left(\alpha_{B}+t_{B}^{3}-t_{B}^{1}\right)^{2}\right] \\
\left.+2 \theta^{3}\left[3 \alpha_{C}^{2}+\left(t_{C}^{1}-t_{C}^{2}\right)^{2}\right]\right\}
\end{gathered}
$$

\section{Appendix 2}

The first-order and second-order conditions of nations’ tariffs on social welfare level are:

$$
\begin{gathered}
\frac{\partial S W_{i}}{\partial t_{i}^{j}}=\frac{\left(4-\theta^{2}\right) \alpha_{i}+\theta\left(8+5 \theta-2 \theta^{2}\right) t_{i}^{k}-(2+\theta)\left(6+3 \theta-2 \theta^{2}\right) t_{i}^{j}}{4 b(2-\theta)^{2}(1+\theta)^{2}} \\
\frac{\partial^{2} S W_{i}}{\partial t_{i}^{j 2}}=-\frac{(2+\theta)\left(6+3 \theta-2 \theta^{2}\right)}{4 b(2-\theta)^{2}(1+\theta)^{2}}<0 \\
D=\left[\begin{array}{ll}
\frac{\partial^{2} S W_{i}}{\partial t_{i}^{j 2}} & \frac{\partial^{2} S W_{i}}{\partial t_{i}^{j} \partial t_{i}^{k}} \\
\frac{\partial^{2} S W_{i}}{\partial t_{i}^{k} \partial t_{i}^{j}} & \frac{\partial^{2} S W_{i}}{\partial t_{i}^{k 2}}
\end{array}\right], \\
D_{1}=\left|\frac{\partial^{2} S W_{i}}{\partial t_{i}^{j 2}}\right|<0, \quad D_{2}=\left|\begin{array}{ll}
\frac{\partial^{2} S W_{i}}{\partial t_{i}^{j 2}} & \frac{\partial^{2} S W_{i}}{\partial t_{i}^{j} \partial t_{i}^{k}} \\
\frac{\partial^{2} S W_{i}}{\partial t_{i}^{k} \partial t_{i}^{j}} & \frac{\partial^{2} S W_{i}}{\partial t_{i}^{k 2}}
\end{array}\right|=\frac{18-11 \theta^{2}+3 \theta^{3}}{2 b^{2}(2-\theta)^{4}(1+\theta)^{2}}>0 .
\end{gathered}
$$

where $i=\mathrm{A}, \mathrm{B}, \mathrm{C} . j, k$ are the import firms in country $i$, and $j \neq k$.

Form Equation (A3), we can see the matrix $\mathrm{D}$ is negative definition and the second-order condition is satisfied.

We can get the nation's import tariff reaction functions From Equation (A1) and the slope are positive $\left(0<\left[\theta\left(8+5 \theta-2 \theta^{2}\right) /(2+\theta)\left(6+3 \theta-2 \theta^{2}\right)\right]<1\right)$, the decision of the optimum import tariff in country A could be described from Figure A1.

\section{Appendix 3. The Impact of Social Welfare for Country C from A-B FTA}

From appendix 1 we can see the social welfare involve the foreign tariffs in country $\mathrm{C}$ is: 


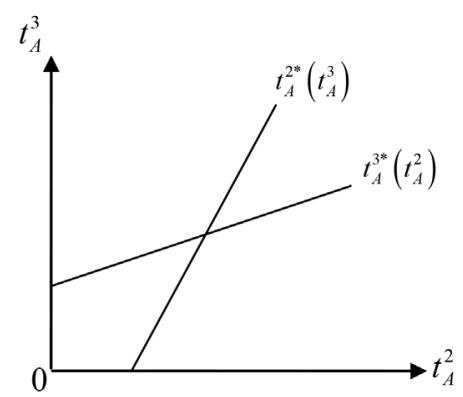

Figure A1. The decision of the optimum import tariff in country A.

$$
2\left\{\left[\left(\alpha_{A}+t_{A}^{3}-t_{A}^{2}\right) \theta-2\left(\alpha_{A}-t_{A}^{3}\right)\right]^{2}+\left[\left(\alpha_{B}+t_{B}^{3}-t_{B}^{1}\right) \theta-2\left(\alpha_{B}-t_{B}^{3}\right)\right]^{2}\right\} / 8 b\left(2-\theta^{2}\right)\left(1+\theta^{2}\right),
$$

the optimal tariffs in country A and B before the establishment of the A-B FTA are

$t_{A}^{2}=t_{A}^{3}=(2+\theta)(2-\theta) \alpha_{A} / 2\left(6+2 \theta-3 \theta^{2}\right)$ and $t_{B}^{1}=t_{B}^{3}=(2+\theta)(2-\theta) \alpha_{B} / 2\left(6+2 \theta-3 \theta^{2}\right)$, we can see the part of the social welfare involve the foreign tariffs in country $\mathrm{C}$ is $\left(\alpha_{A}^{2}+\alpha_{B}^{2}\right)(4-3 \theta)^{2} / 4 b\left(6+2 \theta-3 \theta^{2}\right)^{2}$.

When the A-B FTA established, tariffs will be zero $\left(t_{A}^{2}=t_{B}^{1}=0\right)$ and the optimal tariffs to country $\mathrm{C}$ are $t_{A}^{3}=(2-\theta) \alpha_{A} /\left(6+3 \theta-2 \theta^{2}\right)$ and $t_{B}^{3}=(2-\theta) \alpha_{B} /\left(6+3 \theta-2 \theta^{2}\right)$, we can see the part of the social welfare in volve the foreign tariffs in country $\mathrm{C}$ is $\left(\alpha_{A}^{2}+\alpha_{B}^{2}\right)(2-\theta)^{2} / b\left(6+3 \theta-2 \theta^{2}\right)^{2}$.

And then we can get the gap from the country C's social welfare level is:

$$
\Delta S W_{C}=\left(\frac{\alpha_{A}^{2}+\alpha_{B}^{2}}{4 b}\right)\left(\frac{4(2-\theta)^{2}}{\left(6+3 \theta-2 \theta^{2}\right)^{2}}-\frac{(4-3 \theta)^{2}}{\left(6+2 \theta-3 \theta^{2}\right)^{2}}\right) \geq 0
$$

The social welfare level of country $\mathrm{C}$ will be rising because of the effect of trade expansion and improved. The country $\mathrm{C}$ optimum import tariff decision only because the size of the domestic market not the foreign markets, so the country $\mathrm{C}$ is still the most suitable tariff results in Appendix 2. 